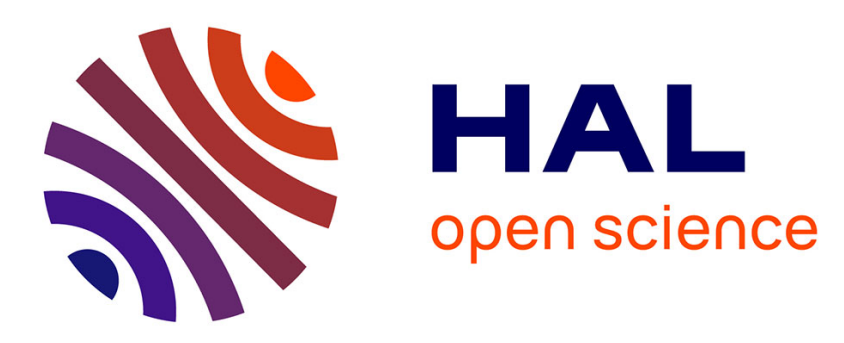

\title{
Dental Pulp Response to RetroMTA after Partial Pulpotomy in Permanent Human Teeth
}

\author{
Hengameh Bakhtiar, Pouyan Aminishakib, Mohammad Reza Ellini, Fereshteh \\ Mosavi, Fatemeh Abedi, Samar Esmailian, Ehsan Esnaashari, Mohammad \\ Hossein Nekoofar, Mehdi Sezavar, Vahid Mesgarzadeh, et al.
}

\section{To cite this version:}

Hengameh Bakhtiar, Pouyan Aminishakib, Mohammad Reza Ellini, Fereshteh Mosavi, Fatemeh Abedi, et al.. Dental Pulp Response to RetroMTA after Partial Pulpotomy in Permanent Human Teeth. Journal of Endodontics, 2018, 44 (11), pp.1692-1696. 10.1016/j.joen.2018.07.013 hal-02103304

\section{HAL Id: hal-02103304 https://hal.science/hal-02103304}

Submitted on 18 Apr 2019

HAL is a multi-disciplinary open access archive for the deposit and dissemination of scientific research documents, whether they are published or not. The documents may come from teaching and research institutions in France or abroad, or from public or private research centers.
L'archive ouverte pluridisciplinaire HAL, est destinée au dépôt et à la diffusion de documents scientifiques de niveau recherche, publiés ou non, émanant des établissements d'enseignement et de recherche français ou étrangers, des laboratoires publics ou privés. 


\title{
Dental Pulp Response to RetroMTA after Partial Pulpotomy in Permanent Human Teeth
}

\author{
Hengameb Bakbtiar, DDS, MSc, ${ }^{*}$ Pouyan Aminishakib, PhD, ${ }^{\ddagger}$ Mobammad Reza Ellini, BSc, ${ }^{* \dagger}$ \\ Fereshteb Mosavi, DDS, * Fatemeh Abedi, DDS, * Samar Esmailian, DDS, * \\ Ehsan Esnaashari, DDS, MSc, * Mobammad Hossein Nekoofar, DDS, MSc, PhD, \\ Mehdi Sezavar, DDS, OMFS, "Vabid Mesgarzadeh, DDS, OMFS, " and Imad About, PhD
}

\section{Abstract}

Introduction: A lack of information exists regarding the efficacy of RetroMTA (BioMTA, Seoul, Korea) directly applied on the pulp in vital pulp therapy. This study was designed to examine the clinical efficacy of RetroMTA compared with ProRoot mineral trioxide aggregate (MTA) (Dentsply Tulsa Dental, Tulsa, OK) for partial pulpotomy. Methods: Partial pulpotomy was performed in 22 healthy human maxillary and mandibular third molars planned for extraction. The teeth were randomly divided into 2 groups $(n=11)$ and underwent partial pulpotomy with RetroMTA and ProRoot MTA as the control. The teeth were then restored with glass ionomer cement. Clinical and electric pulp tests were performed after 1 and 8 weeks. The teeth were radiographed and extracted at 8 weeks. Histologic sections were prepared and analyzed for pulp inflammation and dentinal bridge formation. Data were analyzed using the Mann-Whitney $U$ test. Results: Clinical examination after 1 and 8 weeks showed no sensitivity to heat, cold, or palpation in the ProRoot MTA and RetroMTA groups. Periapical radiographs taken before the extraction of teeth showed no evidence of periapical pathology. Electric pulp testing revealed no sensitivity. Data comparisons using the Mann-Whitney $U$ test showed no significant difference between the materials with regard to the pulp inflammation type, intensity and extension $(P=.3)$, or bridge continuity $(P=.12)$. However, these data revealed a significant difference between the 2 materials in pulp morphology $(P<.05)$ and bridge thickness $(P<.01)$. Conclusions: This is the first work to evaluate a RetroMTA histologic outcome in partial pulpotomy in human permanent teeth. It shows pulp disorganization, an absence of inflammation, and discontinuous mineralization, which may represent a potential drawback with RetroMTA in this indication. (J Endod 2018; $\mathbf{\square}: 1-5$ )

\section{Key Words}

Partial pulpotomy, permanent human teeth, ProRoot MTA, RetroMTA, vital pulp therapy

$\mathrm{M}$ aintaining pulp vitality after carious, traumatic, or iatrogenic injuries remains a challenge. This is particularly true in immature permanent teeth in which pulp vitality leads to complete root formation (1). Thus, vital pulp therapy is favored for continued root development $(2,3)$

Mineral trioxide aggregate (MTA) is a water-based material used for endodontic treatment and pulp capping. It is made of tricalcium silicate, tricalcium aluminate, and bismuth oxide and tetracalcium aluminoferrite. ProRoot MTA (Dentsply Tulsa Dental, Tulsa, OK) sets in moisture and significantly reduces bacterial invasion with a high sealing ability. Additionally, several studies have shown its biocompatibility $(4,5)$ and its capacity to stimulate dentin bridge formation faster than calcium hydroxide (1, 6-9). This explains why ProRoot application for treating pulp wounds $(1,7)$ leads to high success rates in clinical procedures $(6,7,9,10)$. However, MTA has a long setting time and poor handling properties and results in tooth discoloration because of the presence of bismuth oxide as a radiopacifier in its composition $(11,12)$. Researchers attempted to improve MTA by adding a setting accelerator. Although the addition of calcium chloride $\left(\mathrm{CaCl}_{2}\right)$ to MTA significantly decreased the setting time $(13,14)$, white MTA (Dentsply Tulsa Dental) was introduced to avoid tooth discoloration (12), but it has a significantly lower setting time compared with gray MTA (15).

RetroMTA (BioMTA, Seoul, Korea) consists of calcium carbonate $(60 \%-80 \% \mathrm{wt}$ $\%)$, silicon dioxide (5-15 wt\%), aluminum oxide (5-10 wt\%), and calcium zirconia complex (20-30 wt\%) (16). This material has a setting time of 180 seconds, which can be beneficial for single-visit treatments. Investigating cell viability and attachment directly on human pulp cells and the release of calcium from the material were similar to those with ProRoot MTA. Additionally, the levels of vascular endothelial growth factor,

From the *Endodontic Department, Dental Material Research Center, Tehran Dental Branch and ${ }^{\dagger}$ Stem Cell Research Center, Central Tehran Branch, Islamic Azad University, Tehran, Iran; Departments of ${ }^{\ddagger}$ Oral and Maxillofacial Pathology and ${ }^{\S}$ Endodontics, School of Dentistry, Tehran University of Medical Sciences, Tehran, Iran; "Department of Oral and Maxillofacial Surgery, Tehran Dental Branch, Islamic Azad University, Tehran, Iran; and "Aix Marseille University, Centre National de la Recherche Scientifique, Institut des Sciences du Mouvement, Institute Movement Science, Marseille, France.

Address requests for reprints to Prof Imad About, Institut des Sciences du Mouvement (ISM), UMR 7287 CNRS and Université d'Aix-Marseille, Faculté d'Odontologie, 27 BD Jean Moulin, 13385, Marseille Cedex 5, France. E-mail address: imad.about@univ-amu.fr 
angiogenin, and basic fibroblast growth factor were similar to those obtained with ProRoot MTA (16). When RetroMTA was evaluated in pulpotomy, continuous calcified barriers were formed in dog teeth after 4 weeks, showing that the material may be used for pulpotomy in the clinic (5). A single clinical trial was performed with RetroMTA in 3to 10-year-old children undergoing primary teeth pulpotomy. After 12 months, the clinical and radiographic results with RetroMTA were similar to those of MTA, indicating a very high success rate (4).

These data represent the rare published works on RetroMTA and show a lack of information on vital pulp therapy with this material. Additionally, to the best of our knowledge, the use of RetroMTA in adult permanent teeth has never been investigated, and no studies were performed to investigate the histology and inflammatory pulp state after applying this material directly onto the pulp. The aim of this study was to evaluate the pulp response to RetroMTA after partial pulpotomy of human adult third molars.

\section{Material and Methods Teeth Inclusion and Exclusion Criteria}

Twenty-two intact human caries-free maxillary and mandibular third molars scheduled for extraction were selected in patients ranging from 18-32 years old. Teeth with periapical pathology and caries were excluded after radiographic examinations. All the teeth had closed apices. The samples were randomly designated to each group applying block randomization using Excel (Microsoft, Redmond, WA). The sample size was estimated using 2-sample $t$ power analysis with PASS 11 software (NCSS Statistical Software, Chicago, IL) based on a previous study using (17) the following data:

$$
\begin{aligned}
& \alpha=0.05 \\
& \beta=0.2 \\
& \text { Difference }=0.2 \\
& \text { standard deviation }=0.18
\end{aligned}
$$

\section{Operative Procedure}

The experimental rational, clinical procedures, and possible complications of the procedure were explained for the patients beforehand. All experimental procedures were reviewed and approved by the Ethical Committee of Azad University Dental Branch of Tehran, Tehran, Iran, and registered under the Iranian Registry of Clinical Trials (identification number: 2015082420004 N2). Pulp vitality was tested using thermal (Kältespray; M\&W Dental GmbH, Budingen, Germany) and electric (Vitality Scanner pulp vitality tester; SybronEndo, Orange, CA) methods. A standard procedure was used for all patients. Before cavity preparation, teeth were mechanically disinfected with $0.2 \%$ chlorhexidine solution. After local anesthesia with $2 \%$ lidocaine (Daroupakhsh, Tehran, Iran) and rubber dam application, occlusal class I cavities were prepared by using round sterile diamond burs at high speed under airdistilled water spray coolant. An exposure of approximately $1.2 \mathrm{~mm}$ (in diameter) was made with 10 -mm fissure diamond burs $(837 \mathrm{~L} ; \mathrm{D}+\mathrm{Z}$, Kalletal, Germany) under sterile saline cooling. New burs were used for each operation. Bleeding was controlled with a sterile cotton pellet placed onto the pulp exposure sites. Partial pulpotomy was performed for each group as follows:

1. The ProRoot MTA group: ProRoot MTA was prepared by gradually mixing $1 \mathrm{mg}$ of the powder with the liquid within 1 minute according to the manufacturer's instructions until a thick paste with creamy consistency was obtained. The exposed pulp was capped with a 2mm-thick layer of ProRoot MTA, after which a flat, moist cotton pellet was used to shape the ProRoot MTA.
2. The RetroMTA group: exposed pulps and the surrounding dentins were capped with RetroMTA. RetroMTA powder $(0.3 \mathrm{~g})$ was mixed with 3 drops of water with a plastic spatula for 20 seconds until the shiny surface disappeared (based on manufacturer's instructions). Each package was adequate for 1 patient. Based on our inclusion criteria, when a patient was scheduled for more than 1 pulpotomy, the 2 materials were used for that patient.

After partial pulpotomy, the cavities in both groups were restored with glass ionomer cement (Ketac Molar; 3M ESPE, Seefeld, Germany). All patients returned for a clinical examination after 7 days. An additional clinical examination was performed after 8 weeks just before the extraction procedure. One experienced operator performed all the operative procedures. If a patient returned with symptoms or required emergency treatment, the appropriate treatment would have been given to the patient and that patient would have been excluded from the study; however, none of our patients developed symptoms or required emergency treatment.

\section{Clinical Examination}

Clinical tests including the electric pulp test were performed after 1 and 8 weeks to evaluate pulp vitality. At the same visits, the presence of periapical pathology was determined with radiographs. After a treatment period of 8 weeks, the teeth were extracted for histologic evaluations.

\section{Histologic Examination}

As formerly reported, $1 \mathrm{~mm}$ from the extracted teeth apex was cut, and the teeth were fixed using $4 \%$ formaldehyde solution and demineralized (18). Furthermore, 5- $\mu$ m-thick sections were made from formalin-fixed and paraffin-embedded teeth. Samples were stained with hematoxylin-eosin. Finally, the slides were assessed by a pathologist blinded to the patient groups under a light microscope (BX41; Olympus, Tokyo, Japan) using modified criteria based on those of Nowicka et al $(19,20)$ as follows:

1. Type of pulp inflammation: $1=$ no inflammation, $2=$ chronic, $3=$ acute and chronic, and $4=$ acute. When both acute (including PMNs) and chronic (including lymphocytes) inflammatory cell accumulations were observed (light microscopy), the sample was labeled as "mixed" or "acute chronic" inflammation.

2. Intensity of pulp inflammation: $1=$ absent or very few inflammatory cells; 2 = mild, $<10$ inflammatory cells; $3=$ moderate, $10-25$ inflammatory cells; and $4=$ severe, $>25$ inflammatory cells. When no inflammatory cells or less than 5 inflammatory cell aggregations were observed, it was considered as "absent or very few inflammatory cells."

3. Extension of pulp inflammation: $1=$ absent; 2 = mild (inflammatory cells only next to the pulp exposure site), $3=$ moderate (inflammatory cells observed in part of the coronal pulp), and $4=$ severe (all coronal pulp is infiltrated)

4. Dentin bridge thickness: $1=>0.25 \mathrm{~mm}, 2=0.1-0.25 \mathrm{~mm}, 3=$ $<0.1 \mathrm{~mm}$, and $4=$ partial or absent bridge. The thickness of the dentinal bridge was measured at the thickest, thinnest, and midmost point areas of the bridge. The average of the 3 values was calculated.

5. Morphology and continuity of the dentin bridge: 1 = formation of a complete dentinal bridge, 2 = formation of a discontinuous dentin bridge, and $3=$ no sign of dentin formation

6. Pulp tissue organization and morphology: $1=$ normal pulp morphology, 2 = disorganization of pulp tissue beneath the cavity, and 3 = disorganization of the entire pulp 
Basic Research-Biology

Data were analyzed using SPSS version 22 (IBM Corp, Armonk, $\mathrm{NY})$. Categoric variables are reported as frequency and percentage in each study group. To compare the distribution of dependent variables between the studied groups, the Mann-Whitney $U$ test was performed. $P$ values $<.05$ were considered as statistically significant.

\section{Histologic Evaluation}

\section{Results}

Pulp histology under RetroMTA presented no inflammation in 8 of 11 of the teeth (Table 1). Teeth showed completely (7/11) or partially (3/11) disorganized pulp tissue (Table 2). A complete dentinal bridge was formed in 3 of 11 cases, and it was incomplete in 7 of 11 cases (Table 2). RetroMTA-treated samples showed tissue disorganization beneath the cavity and dispersed mineralization formations (Table 2).

Pulp histology under ProRoot MTA showed that none of the samples had an inflammation (Table 1). Pulp disorganization was observed beneath the cavity in 2 of 11 cases, and complete disorganization was observed in 3 of 11 cases. Complete dentinal bridge was formed in 7 of 11 teeth, and an incomplete bridge was observed in 4 of 11 cases. Most pulps treated with ProRoot MTA showed normal pulp morphology or limited tissue disorganization beneath the cavity (8/11) and complete dentin bridge formation (7/11) (Table 2).

Data comparisons using the Mann-Whitney $U$ test showed no significant difference between the materials with regard to the pulp inflammation type, intensity and extension $(P=.3)$, and bridge continuity $(P$ $=.12)$ (Tables 1 and 2). However, these data revealed a significant difference between the 2 materials in pulp morphology $(P<.05)$ and bridge thickness $(P=.002)$ (Table 2).

These data were also compared with each other in Table 3 according to the following criteria:

1. Complete bridge formation with normal pulp morphology

2. Complete bridge formation with pulp tissue disorganization beneath the cavity

3. Discontinuous bridge formation with pulp tissue disorganization beneath the cavity

4. Discontinuous bridge formation with complete pulp tissue disorganization

5. No bridge formation and complete pulp tissue disorganization

TABLE 1. Type and Intensity of Pulp Inflammation after Partial Pulpotomy with RetroMTA and ProRoot Mineral Trioxide Aggregate (MTA) after 8 Weeks $(P=.300)$

\begin{tabular}{|c|c|c|c|c|}
\hline \multirow{2}{*}{$\begin{array}{c}\text { Materials } \\
\text { Index }\end{array}$} & \multicolumn{2}{|c|}{$\begin{array}{c}\text { RetroMTA } \\
(n=11)\end{array}$} & \multicolumn{2}{|c|}{$\begin{array}{l}\text { ProRoot } \\
(n=11)\end{array}$} \\
\hline & $n$ & $\%$ & $n$ & $\%$ \\
\hline \multicolumn{5}{|c|}{ Intensity of pulp inflammation } \\
\hline Absent & 8 & 72 & 11 & 100.0 \\
\hline Mild & 3 & 28 & 0 & 0.0 \\
\hline Moderate & 0 & 0.0 & 0 & 0.0 \\
\hline Severe & 0 & 0.0 & 0 & 0.0 \\
\hline \multicolumn{5}{|c|}{ Type of pulp inflammation } \\
\hline No Inflammation & 8 & 72 & 11 & 100.0 \\
\hline Chronic & 3 & 28 & 0 & 0.0 \\
\hline Chronic and cute & 0 & 0.0 & 0 & 0.0 \\
\hline Acute & 0 & 0.0 & 0 & 0.0 \\
\hline \multicolumn{5}{|c|}{ Extension of pulp inflammation } \\
\hline Absent & 8 & 72 & 11 & 100.0 \\
\hline Mild & 0 & 0.0 & 0 & 0.0 \\
\hline Moderate & 3 & 28 & 0 & 0.0 \\
\hline Severe & 0 & 0.0 & 0 & 0.0 \\
\hline
\end{tabular}

TABLE 2. Histologic Analysis on Hard Tissue Formation

\begin{tabular}{|c|c|c|c|c|}
\hline \multirow[b]{2}{*}{ Materials } & \multicolumn{2}{|c|}{$\begin{array}{c}\text { RetroMTA } \\
(n=11)\end{array}$} & \multicolumn{2}{|c|}{$\begin{array}{c}\text { ProRoot } \\
\text { MTA } \\
(n=11)\end{array}$} \\
\hline & $n$ & $\%$ & $n$ & $\%$ \\
\hline \multicolumn{5}{|l|}{ Pulp tissue organization } \\
\hline Normal pulp tissue & 1 & 9 & 6 & 55 \\
\hline $\begin{array}{l}\text { Disorganization } \\
\text { beneath the cavity }\end{array}$ & 3 & 27 & 2 & 18 \\
\hline $\begin{array}{l}\text { Disorganization of the } \\
\text { entire pulp tissue }\end{array}$ & 7 & 64 & 3 & 27 \\
\hline$P$ value $P$ P & \multicolumn{4}{|c|}{.047} \\
\hline \multicolumn{5}{|c|}{ Dentinal bridge morphology } \\
\hline $\begin{array}{l}\text { Complete dentinal } \\
\text { bridge }\end{array}$ & 3 & 27 & 7 & 64 \\
\hline Discontinuous bridge & 7 & 64 & 4 & 36 \\
\hline $\begin{array}{l}\text { No signs of } \\
\text { mineralization }\end{array}$ & 1 & 9 & 0 & 0.0 \\
\hline$P$ value & \multicolumn{4}{|c|}{.116} \\
\hline Dentinal bridge thicknes & & & & \\
\hline More than $0.25 \mathrm{~mm}$ & 0 & 0.0 & 5 & 45 \\
\hline Between 0.1-0.25 mm & 5 & 45 & 6 & 55 \\
\hline Less than $0.1 \mathrm{~mm}$ & 6 & 55 & 0 & 0.0 \\
\hline$P$ value & \multicolumn{4}{|c|}{.002} \\
\hline
\end{tabular}

MTA, mineral trioxide aggregate

The comparative results shown in Table 3 indicate a significantly better outcome with the ProRoot MTA group. The ProRoot MTA results shows a $55 \%$ normal pulp morphology and complete dentin bridge formation (Fig. $1 C$ and $D$ and Table 3). RetroMTA showed a total of $27 \%$ complete bridge formation and $64 \%$ incomplete or no bridge formation (Fig. $1 A$ and $B$ and Table 3 ).

\section{Clinical and Radiographic Results}

Clinical examination after 1 and 8 weeks showed no sensitivity to heat, cold, or palpation in the ProRoot MTA and RetroMTA groups. Periapical radiographs taken before the extraction of teeth showed no evidence of periapical pathology. The electric pulp test revealed no sensitivity.

\section{Discussion}

This study evaluating RetroMTA effects on human third molars treated by partial pulpotomy revealed the formation of a discontinuous bridge in most cases under the material within the pulp tissue with no significant inflammatory reaction in partially or completely disorganized dental pulp. This contrasts with ProRoot MTA, which resulted in complete dentin bridge formation in most of the teeth with no inflammation and normal pulp morphology.

The absence of inflammation with RetroMTA may be caused by the absence of toxic components in its composition and its alkaline $\mathrm{pH}$, which is known to cause superficial necrosis by producing coagulation in the underlying pulp $(16,21)$. Indeed, RetroMTA has a high alkalinity, which rises initially to $12.5(3,22)$ and decreases to 8 after 4 weeks in an in vivo environment (22). Additionally, the alkaline-related biological properties of pulp capping are key factors for the success of pulp capping materials. The release of hydroxyl ions during the hydration reaction creates an adverse environment for bacterial survival and proliferation (23). These antibacterial properties are primarily required at the dentin/restoration interface where residual bacteria could increase the risk of inflammation, reinfection, and secondary caries (24).

The fact that both ProRoot MTA and RetroMTA induced mineralization at the interface with the pulp tissue may be attributed to their 


\section{Basic Research-Biology}

TABLE 3. Cumulative Comparison between Bridge Formation and Disorganization with ProRoot Mineral Trioxide Aggregate (MTA) and RetroMTA

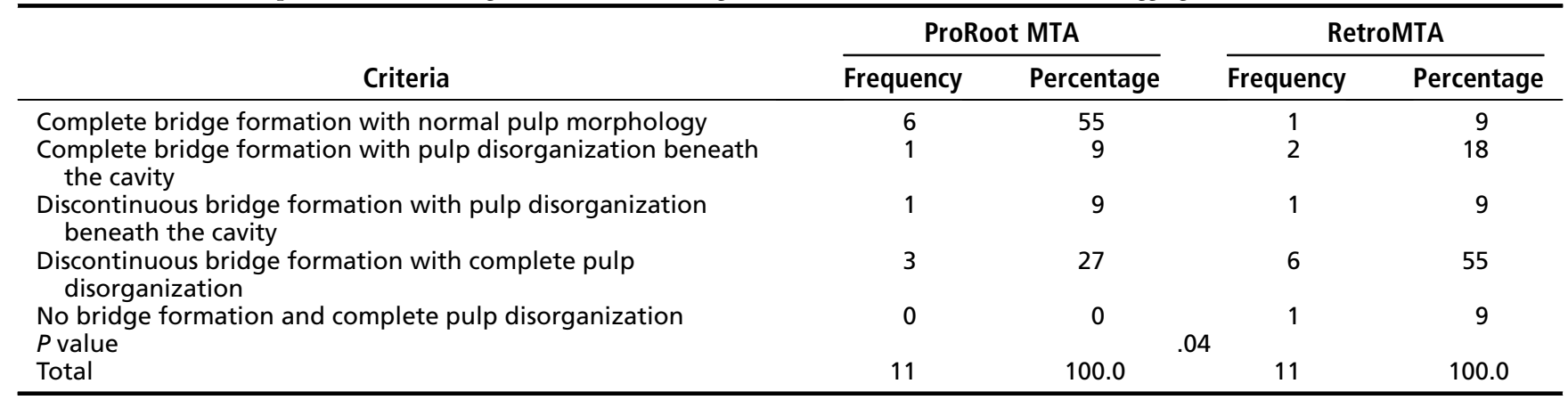

calcium oxide content, which can form calcium hydroxide in the presence of water (25). Calcium hydroxide has been described as a compound that affects the microvasculature to reduce the plasma outflow and induces mineralization in the adjacent pulp tissue (13).

Additionally, the release of calcium from the material stimulates dentin bridge formation (3). ProRoot MTA also releases calcium ions and alkalinizes its local environment. Increased $\mathrm{pH}$ leads to an initial inflammatory reaction followed by the formation of reparative dentin (26).

Dentine bridge formation provides a barrier against coronal microleakage and bacterial invasion. A complete and continuous dentin bridge is more effective in underlying pulp protection than a disorganized and discontinuous bridge (5). Thus, in vital pulp therapy, dentin bridge formation is a desirable barrier against coronal microleakage and bacterial invasion (27).

A partial pulpotomy was chosen to investigate the pulp response to RetroMTA because of a substantial area of contact between the pulp and the biomaterial and the prospects of hard tissue formation (2). In this study, although ProRoot MTA samples formed a continuous and thick dentinal bridge, $64 \%$ of RetroMTA samples showed irregular hard tissue formation, and $9 \%$ had no hard tissue formation. This can be linked to the fact that $100 \%$ of the ProRoot MTA group were free from any inflammation, whereas only $72 \%$ of the RetroMTA group showed no inflammation (Table 1).

A previously published work showed that RetroMTA leads to reparative tubular dentin formation in dog teeth partial pulpotomy with no pulp inflammation or disorganization $(5,27)$. In agreement with this study, no pulp inflammation was observed in our work. The absence of inflammation may be caused by the absence of toxic substances in the material composition and the resulting antibacterial effects of the alkaline $\mathrm{pH}$. By contrast, the pulp appeared disorganized, and mineralization was discontinuous in our work. Although we cannot provide a rational explanation on the origin of the pulp disorganization in our work, which may be caused by
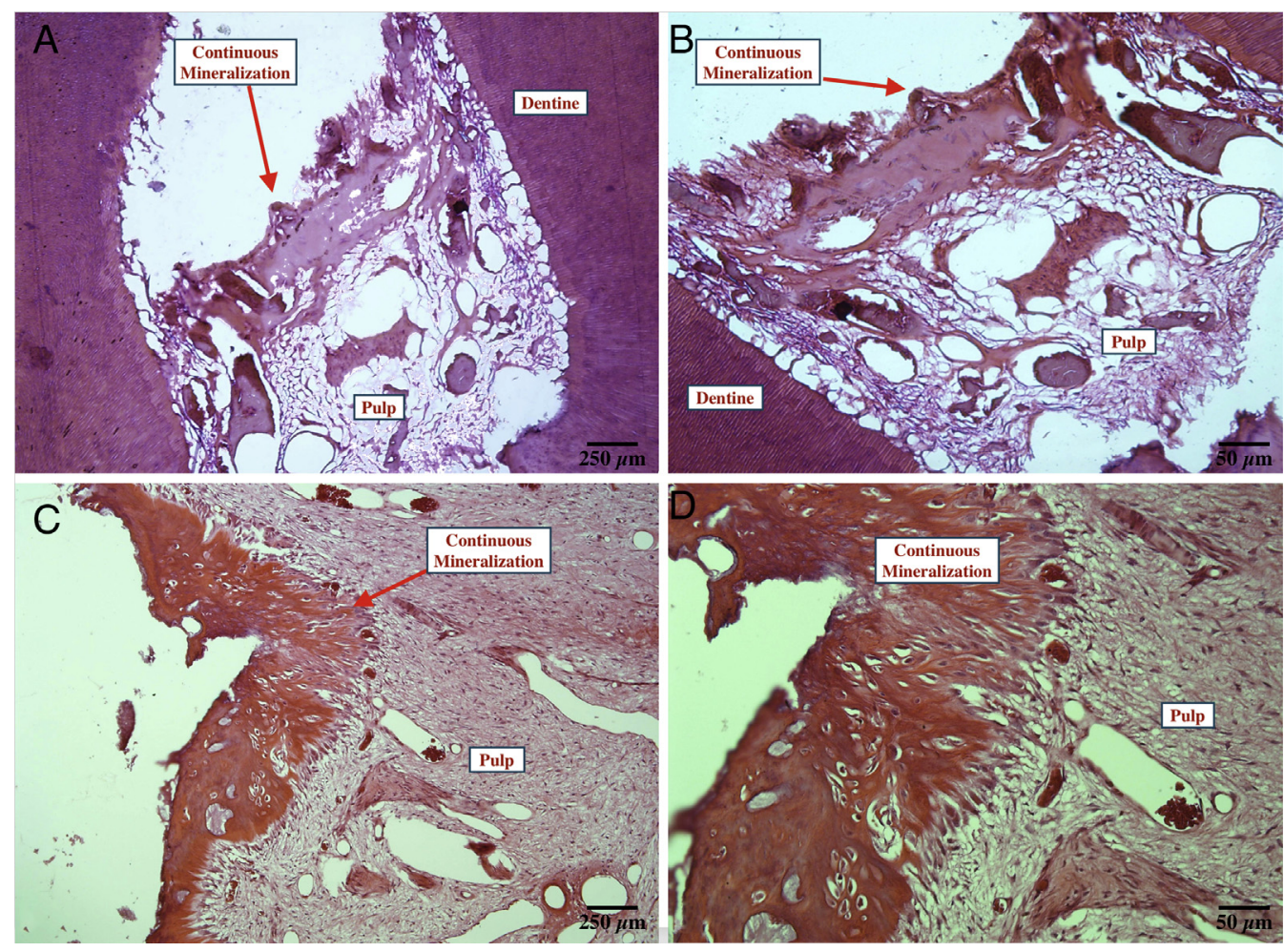

Figure 1. Partial pulpotomy with RetroTA shows $(A)$ formation of a discontinuous dentinal bridge $(\times 40)$ and $(B)$ pulp tissue disorganization $(\times 200)$. Dentinal bridge formation in ProRoot MTA shows $(C)$ continuous bridge formation $(\times 40)$ with $(D)$ normal pulp morphology $(\times 200)$. 
interspecies differences, the discontinuous mineralization may not be sufficient to provide the marginal sealing of the pulp under the definitive restorative material.

When RetroMTA was evaluated in a clinical trial in primary teeth pulpotomy, radiographic and clinical success similar to that obtained with ProRoot MTA was reported (4). The absence of inflammation after 8 weeks in our investigation may explain the observed absence of radiographic and clinical signs in this clinical trial. However, our work was performed on permanent teeth, which may represent a limit of indication of this material.

Additionally, in our study, partial pulpotomy was performed on intact vital teeth that initially had healthy pulp tissue. All teeth were treated with a rigorous protocol for the partial pulpotomy, including rubber dam isolation and hemostasis with a disinfecting irrigant to minimize the risk of bacterial infection. Because no additional infections were detected, we attribute the differences in pulpal response to differences between the pulpotomy materials. However, this may appear as a limitation of our protocol because pulpotomy is not performed on healthy teeth in the clinic but rather on carious teeth.

When compared with ProRoot MTA, although RetroMTA has a short setting time, the clinical outcome with this material was clearly less favorable than that of ProRoot MTA in partial pulpotomy of permanent teeth. Finally, this study was on permanent teeth, which may represent the limit of material application.

\section{Conclusion}

This is the first work to evaluate a RetroMTA histologic outcome in partial pulpotomy in human permanent teeth. It shows pulp disorganization, an absence of inflammation, and discontinuous mineralization, which may represent a potential drawback with RetroMTA in this indication.

\section{Acknowledgments}

The authors deny any conflicts of interest related to this study.

\section{References}

1. Laurent P, Camps J, About I. Biodentine(TM) induces TGF-beta1 release from human pulp cells and early dental pulp mineralization. Int Endod J 2012;45:439-48.

2. Barrieshi-Nusair KM, Qudeimat MA. A prospective clinical study of mineral trioxide aggregate for partial pulpotomy in cariously exposed permanent teeth. J Endod 2006;32:731-5.

3. Tuna D, Olmez A. Clinical long-term evaluation of MTA as a direct pulp capping material in primary teeth. Int Endod J 2008;41:273-8.

4. Kang CM, Kim SH, Shin Y, et al. A randomized controlled trial of ProRoot MTA, OrthoMTA and RetroMTA for pulpotomy in primary molars. Oral Dis 2015;21:785-91.

5. Lee H, Shin Y, Kim SO, et al. Comparative study of pulpal responses to pulpotomy with ProRoot MTA, RetroMTA, and TheraCal in dogs' teeth. J Endod 2015;41: $1317-24$.
6. Accorinte ML, Loguercio AD, Reis A, et al. Response of human dental pulp capped with MTA and calcium hydroxide powder. Oper Dent 2008;33:488-95.

7. Eskandarizadeh A, Shahpasandzadeh MH, Shahpasandzadeh M, et al. A comparative study on dental pulp response to calcium hydroxide, white and grey mineral trioxide aggregate as pulp capping agents. J Conserv Dent 2011;14:351-5.

8. Nair PN, Duncan HF, Pitt Ford TR, Luder HU. Histological, ultrastructural and quantitative investigations on the response of healthy human pulps to experimental capping with mineral trioxide aggregate: a randomized controlled trial. Int Endod J 2008;41:128-50.

9. Faraco IM Jr, Holland R. Response of the pulp of dogs to capping with mineral trioxide aggregate or a calcium hydroxide cement. Dent Traumatol 2001; $17: 163-6$.

10. Zarrabi MH, Javidi M, Jafarian AH, Joushan B. Histologic assessment of human pulp response to capping with mineral trioxide aggregate and a novel endodontic cement. J Endod 2010;36:1778-81.

11. Parirokh M, Torabinejad M. Mineral trioxide aggregate: a comprehensive literature review-part III: clinical applications, drawbacks, and mechanism of action. J Endod 2010;36:400-13.

12. Dammaschke T, Gerth HU, Zuchner H, Schafer E. Chemical and physical surface and bulk material characterization of white ProRoot MTA and two Portland cements. Dent Mater 2005;21:731-8.

13. Bortoluzzi EA, Broon NJ, Bramante CM, et al. Mineral trioxide aggregate with or without calcium chloride in pulpotomy. J Endod 2008;34:172-5.

14. Villat $\mathrm{C}$, Tran $\mathrm{XV}$, Pradelle-Plasse $\mathrm{N}$, et al. Impedance methodology: a new way to characterize the setting reaction of dental cements. Dent Mater 2010;26:1127-32.

15. Islam I, Chng HK, Yap AU. Comparison of the physical and mechanical properties of MTA and Portland cement. J Endod 2006;32:193-7.

16. Chung CJ, Kim E, Song M, et al. Effects of two fast-setting calcium-silicate cements on cell viability and angiogenic factor release in human pulp-derived cells. Odontology 2016;104:143-51.

17. Aeinehchi M, Eslami B, Ghanbariha M, Saffar AS. Mineral trioxide aggregate (MTA) and calcium hydroxide as pulp-capping agents in human teeth: a preliminary report. Int Endod J 2003;36:225-31.

18. Tecles 0 , Laurent $P$, Zygouritsas S, et al. Activation of human dental pulp progenitor/ stem cells in response to odontoblast injury. Arch Oral Biol 2005;50:103-8.

19. Nowicka A, Lipski M, Parafiniuk M, et al. Response of human dental pulp capped with biodentine and mineral trioxide aggregate. J Endod 2013;39:743-7.

20. Bakhtiar H, Nekoofar MH, Aminishakib P, et al. Human pulp responses to partial pulpotomy treatment with TheraCal as compared with Biodentine and ProRoot MTA: a clinical trial. J Endod 2017;43:1786-91.

21. Souza LC, Yadlapati M, Dorn SO, et al. Analysis of radiopacity, $\mathrm{pH}$ and cytotoxicity of a new bioceramic material. J Appl Oral Sci 2015;23:383-9.

22. bioMTA. RetroMTA. Available at: http://www.biomta.com/shop/eng/product_5.php? \&. Accessed March 4, 2018.

23. Siqueira JF Jr, Lopes HP. Mechanisms of antimicrobial activity of calcium hydroxide: a critical review. Int Endod J 1999;32:361-9.

24. Poggio C, Beltrami R, Colombo M, et al. In vitro antibacterial activity of different pulp capping materials. J Clin Exp Dent 2015;7:e584-8.

25. Qudeimat MA, Barrieshi-Nusair KM, Owais AI. Calcium hydroxide vs mineral trioxide aggregates for partial pulpotomy of permanent molars with deep caries. Eur Arch Paediatr Dent 2007:8:99-104.

26. Gandolfi MG, Siboni F, Prati C. Chemical-physical properties of TheraCal, a novel light-curable MTA-like material for pulp capping. Int Endod J 2012; 45:571-9.

27. Woodmansey KF, Kohout GD, Primus CM, et al. Histologic assessment of Quick-Set and mineral trioxide aggregate pulpotomies in a canine model. J Endod 2015;41: 1626-30. 